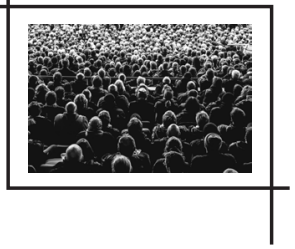

\title{
READING IN COGNITIVE NARRATOLOGY AND DISTANT READING IN THE DIGITAL HUMANITIES APPROACH
}

\author{
David Hoyos García*
}

\begin{abstract}
This essay proposes to make a comparison between cognitive narratology, which studies narrative in its many forms, emphasizing mental/biological processes as similar in reader and author, and the digital humanities' distant reading approach, which identifies literary systems and forms more globally, drawing on the computer as a tool for interpretation. The main ideas of cognitive narratology developed by one of its main theorists, David Herman, are presented focusing on the definition and relationships between reader and text. Cognitive narratology as an interdisciplinary approach towards close reading is mentioned to dialogue with the main topics of the digital humanities literary approach, especially the ideas delineated by Franco Moretti. The contrast of both approaches will focus on the role of the reader by finding some contact points between them.
\end{abstract} Keywords: Digital humanities. Distant reading. Cognitive narratology. Close reading. Reading experience.

Cognitive narratology as an approach for literature is configured under diverse paradigms of reading and considers multiple contact points with other currents such as formalism, reader-response theory, and psychoanalysis, to name a few. In these approaches, a "deep reading" constitutes the base for understanding the text and the author, its meaning, and different intentions. In this text, I will analyze reading regarding two approaches: cognitive narratology and distant reading in digital humanities. Cognitive narratology studies narrative in its many forms, emphasizing mental/biological processes' similarity in reader and author, whereas digital humanities' distant reading works to identify literary systems and forms more globally, drawing on the computer as a tool for interpretation.

Stanley Fish (2010), as a representative theorist of a (implied) reader theory, has proposed a response to new criticism that focuses on the experience of the reader and argues that the meaning of a text is a process rather than a final product. In the reader-response theory, the reader gives shape, structure, meaning and makes the text a living object. In this case, the reader becomes political, and the reception or the critique of a text will be determined by

*PhD Candidate in Literature, McGill University, Montreal. E-mail: david.hoyosgarcia@mail.mcgill.ca 
the different locations, affinities, previous experiences, context of that reader. Thus, as Fish (2010, p. 1982) argues, "readers' activities are at the center of attention, where they are regarded not as leading to meaning but as having meaning". The role of the reader in such cases means that the reader's experience cannot be separated from the meaning of a literary text and, more precisely, readers make the meaning of the text.

Even if today we can agree with this concept of the reader, it has changed in the current discourse brought by digital humanities, considering that now we are not talking only about literature, but about a network of knowledge of which literature is a part. Under this new discourse, "the reader" must be reinterpreted as "the user": a sort of entity that has the power to take distance from a text and see it as a part of a global corpus and, at the same time, to go as deep as the text requires. According to Nishant Sha (2015), in The reader in digital humanities, "the task of making meaning, curating information, and presenting it in parsed formats has been transferred to the predictive algorithm and the self-learning scripts", giving the user only the role of making sense, and from that perspective, the notion of readership has been reduced to a software system and a "friendly and intuitive" user interface. This is only a point of view that considers digital humanities pot-humanism in the sense that the computer becomes a kind of reader but without the capacity to make meaning.

Fish's and Sha's ideas of the reader prompt us to consider, then, the reader as an active agent, which is one of the fundamental paradigms contemplated in the cognitive narratology approach. This approach suggests that a deep reading must be considered a close reading; that is, a detailed interpretation of a text passage to determine central themes and how these themes are developed. We can use the ideas of the reading and reader as a point of contrast between the main aspects of both cognitive narratology and a digital humanities approach to literature. Consequently, the main aim of this essay is to explore the ways in which these theories articulate the relationship between the reader and the text.

To give a structure to the essay, I will divide it into three sections. First, I will present the main ideas of cognitive narratology developed mainly by one of its main theorists, David Herman, in three of his texts: Narrative theory and the cognitive sciences, "Cognitive narratology" and The emergence of mind: representation of consciousness in narrative discourse in English. I will focus on the definition and relationships between reader and text. Next, I will explore cognitive narratology as an interdisciplinary approach towards close reading. To finish, I will take all the aforementioned ideas of cognitive narratology in order to dialogue with the main topics of the digital humanities literary approach, especially the ideas delineated by Franco Moretti in two of his most representative texts: Distant reading and Graphs. The contrast of both approaches will focus on the role of the reader by finding some contact points between them. 


\section{COGNITIVE NARRATOLOGY}

In the Narrative theory and the cognitive sciences, Herman (2003) proposes an interdisciplinary approach to the narrative theory, called the cognitive turn, which is the study of various forms of verbal art and particular narratives. This cognitive turn has become increasingly open to knowledge about the developments in the cognitive sciences. He also states that we must begin by considering that "in narratological literature, narrative is broadly defined as an organized representation of a sequence of events" (HERMAN, 2003, p. 2). These events implicate specific transitions of time and place. In the same order of ideas, Monika Fludernik (2008), in Histories of narrative theory (II): from structuralism to the present, proposes that the narrative theory reoriented itself toward the cognitive roots. She states that the cognitivist turn in narrative study concerns two basic levels: "it focuses on human's perceptions of actions and events from a cognitive viewpoint, and also, it analyzes narrative structures and how these obey fundamental cognitive parameters or frames" (FLUDERNIK, 2008, p. 49). In "Multimodal storytelling and identity construction in graphic narrative", Herman (2008, p. 195) defines cognitive narratology as "the study of mind-relevant aspects of storytelling practices". This definition proposes that cognitive narratology is transmedia, involving multiple methods of analysis which consider diverse narrative corpora that include fictional and nonfictional print; computer-mediated narratives, such as hypertext fictions, e-mail novels, and blogs; comics and graphic novels; cinematic narratives; storytelling in face-to-face interaction; and other instantiations of the narrative text type.

For Herman (2003), there's a little boundary between the reader and the author and it is justified by the studies of mental representations (mental models of characters, episodes, and story settings) and cognitive processes (the storage of situations and events in short- and longterm memory) in people's ability to make sense of stories. On the other hand, studies examine narrative itself as an instrument of sense-making, a semiotic and representative resource that enables humans to make their way in a sometimes confusing and often difficult world.

With these two approaches, we can consequently infer two strategies for studying the ensemble of narrative and intelligence: stories function as a target of interpretation and as a means for making sense of an experience or a resource for structuring and comprehending the world. It means that, in one stage, "making sense of stories", narrative can be viewed as a discourse in which producers, as well as interpreters of stories, use linguistic resources to interact. In this view, linguistic resources mediate authors and producers, and interpreters compose stories. Stories comprehend events, places, characters, and objects, and interpreters (Herman says "listeners and readers") make sense of conversational and literary experiences to draw a core idea of the story. The other strategy is "stories as sense-making", which sees narrative "as an instrument for the exercise or even enhancement of cognitive abilities, and not just a target for cognition" (HERMAN, 2003, p. 13). 
In The emergence of mind: representation of consciousness in narrative discourse in English, the main objective is to provide strategies for reading and the representation of that consciousness by suggesting a variety of analytic approaches to represent the mind in stories. Herman (2011, p. 7) states that

characterizing narrative fiction has a power to reveal the contents of mind: narrative fiction is the only literary genre, as well as the only kind of narrative in which the unspoken thoughts, feelings, perceptions of a person other than the speaker can be portrayed.

The reader does explore the implications or the notion of langue or linguistic systems. In the terms of Saussure (2010, p. 851): the linguistic system "was at once a mental construct and a social fact", and he defended that linguistic competence is a function of the cognitive equipment that speakers acquire when they "internalize or assimilate the linguistic system associated with a language". This is to say that the whole cognitive approach will use three elements for narratology: "semiotic structures, cognitive resources, and social conditions and processes" (HERMAN, 2003, p. 11).

Cognitive sciences and cognitive narratology, according to Herman (2003), can be seen as an effort to understand how people weave a story by relying on abilities they possess as language-using and thinking social beings or, in other words, how narrative can be interpreted as a "way of knowing, interacting, and communicating" (HERMAN, 2003, p. 11). So, finally, the role of the reader is to wave the meaning and sense of the story, which demands a very involved reading. Additionally, in cognitive narratology, stories constitute a target of interpretation.

For that, according to Herman (2003), key questions for cognitive narratology include what cognitive processes support narrative understanding, allowing readers, viewers, or listeners to construct mental models of the worlds evoked by stories? How do they use medium-specific cues to build on the basis of the discourse or subject a chronology for events or fabula (what happened, when, or in what order?)? What is a broader temporal and spatial environment for those events (when in history did these events occur, and where geographically?)? An inventory of the characters involved? And a working model of what it was like for these characters to experience the more or less disruptive or non-canonical events that constitute a core feature of narrative representations (HERMAN, 2013)?

Cognitive narratology uses the concept of script for representing an expected sequence of events (frames) stored in the memory. This concept explains how people can build up "complex interpretations of stories on the basis of very few textual or discursive cues" (HERMAN, 2003, p. 10). At this point, Herman introduces the concept of "experiential repertories" that are narratologies stored in the form of scripts and those enable readers or listeners of stories to "fill in the blanks". From this perspective, this is what makes a story a story and, for that 
matter, how "narrative-like" a given story seems to be and can be explained in terms of the relation between the explicit prompts included in a text or a discourse and the scripts on which readers or listeners rely in processing those prompts; so, it shows the necessity of viewing the narrative itself as a relational construct. Stories should be construed as the pairing or blending of semiotic structures with cognitive resources (HERMAN, 2003, p. 10).

With reader-response, a deep reading must be subscribed as a close reading in cognitive narratology. The reader as an interpreter can use the text for creating the meaning and sense to what is said or written. Under this perspective, we must consider as well that conversation analysis and narrative in the oral language can constitute a prototype for literary and written narrative. Following Herman's essay "Stories as a tool for thinking", in Narrative theory and the cognitive sciences, we can infer that the reader:

incorporates stories into a wide array of practices, using narrative as a problem-solving strategy in many contexts. In this sense, narrative functions as a powerful and basic tool for thinking, enabling users of stories to produce and interpret literary texts (HERMAN, 2003, p. 163).

Producing and interpreting are, thus, interconnected actions by readers, and we can conclude, under this point of view, that the reader can be an author as well. It is also necessary to consider that narrative, in its various forms, is the core of cognitive narratology, so the story (written or oral) can be considered as a cognitive artifact that can be used by users to be reinvented or interpreted and this marks the relationship between reader and text.

To put these ideas of cognitive narratology in the context of literary theory, the Michel Tournier's novel, Vendredi ou les limbes du Pacifique (1972), can be brought as an example. The role of Tournier as an author of Friday can achieve rich importance if we consider that he was making a critical rewriting of Robinson Crusoe, the novel by Daniel Defoe. With this novel, Tournier, through a close reading of Defoe's novel, ponders the significance of literature to lie in its very ability to tell stories that transform our ways of experiencing intertextuality with a previously known text. He establishes a critical dialogue that takes the form of rewriting stories. Under a cognitive approach, a way of reinterpreting that history is chosen by Tournier when replicating Defoe's novel to represent a process whereby Robinson, through encountering Friday and learning to relate to him, gradually leaves behind the Western manipulative and colonialist worldview. From the point of view of the characters, Friday is constructed under the assumption that Robinson and Friday experience a need for identity and meaning in their lives, for example, Robinson finds in his logbook a way for shaping his experiences and for orienting himself in the world and his relationship with Friday and Speranza. For Robinson, the logbook is a narrative that gives him a place for interpreting his experiences in a "novel form", in which he relates to himself by exploring 
cognitive narrative models (i.e. language) and by narrating himself, making reinterpretation of reality become storytelling.

Until now, I have presented the main ideas about the reader in cognitive narratology from a close reading. In this second, part I will bring ideas of the digital humanities approach to literary studies, fundamentally the idea of distant reading and how it can open the field to analyze later the contact points with cognitive narratology.

\section{DIGITAL HUMANITIES APPROACH TO LITERATURE}

Digital humanities is a field of study and research at the intersection of the humanities, computer sciences (KIRSCHENBAUM, 2012). So, it is a multidisciplinary field that involves the research, analysis, synthesis, and presentation of information in electronic form and this emerges due to the developments in computing and their performative and analytical capacity for creating an environment for humanities research and practice. Digital humanists create digital artifacts and models for studying how these digital media affect the disciplines in which they are used and, for that, the computational methods used in this field cut across disciplinary practices to provide shared focal points, such as the preservation and curating of digital data. If literary studies are part of the humanities, then a digital humanities approach to literary studies can raise a new way of reading. In other words, literary analysis, as part of the humanities, is permeated by the digital, which revaluates the concept of reading and text and modifies reading and writing practices and their analysis.

In an essay called Distant reading, Franco Moretti (2013) argues that if we want to write a history of literature, it will be necessary to develop a distant reading. He establishes that if we decide to create a project such as the analysis of a historic literary period, it would take a lot of time to read each of the novels (if analyzing novels only); and if we are interested in getting close to each one of those works, a close reading would not be efficient unless we work with a small canon. The more ambitious a corpus analysis project, the greater must the distance be. Moretti $(2013$, p. 49) defends the thesis that "if we want to understand the system in its entirety, we must accept losing something, and that's the price payed for theoretical knowledge". In other words, the fact of reading distantly can help to understand the way a whole corpus or canon interacts within itself or even how it interacts with another corpus or canon. Jänicke, Franzini, Scheuermann and Cheema, $(2015$, p. 84) summarizes distant reading and compare it with close reading:

while close reading retains the ability to read the source text without dissolving its structure, distant reading does the exact opposite. It aims to generate an abstract view by shifting from observing textual content to visualizing global features of a single or of multiple text(s). 
For Moretti (2013), literature cannot be considered as individual novels written by authors separately, but as a whole system of interactions of authors and political events. In fact, a close reading of novels can help critics or readers to understand very particular details of the author and what he/she finally wanted to write, but it will not give any and not even a few marks or conclusions if, as readers, we want to understand the whole. And this is one of the reasons why Moretti (2013, p. 56) calls literature a "system of variations". Another important point in the theory of distant reading is that, according to Moretti (2013, p. 59), "forms are the abstract of social relationships" and then he states that "formal analysis is in its own modest way an analysis of power". By this, Moretti (2010, p. 2439) criticizes not only formal analysis theories, but he also makes a relationship between literature and power considering also social classes in an implicit way; and this critique will be further developed in Graphs, in which he studies genres and establishes that they "reflect the new balance between socialization and individuality, and also between mobility and interiority". His three essays in this work look to analyze genre change of historical novels (graphs), to illustrate geographical aspects of novels (maps), and to classify different types of detective stories (trees). According to the author, reading becomes, then, a case of understanding the whole. In the same work, he outlines the many published books that are not accounted for in the literary canon in an attempt to "shift our focus" (MORETII, 2010, p. 2441). For example, while some of these many unaccounted novels may have been popular in their time, many have most likely not. Moretti (2010) proposes that giving these novels the same weight given to those we consider integral components of the literary canon does not accurately represent the influence of literature; so, from this assumption, we can infer that this approach focuses on analyzing literature away from literary interpretation.

Another reason that justifies distant reading is that a formal analysis (in this case, a close reading) will also involve linguistic competencies because "studying how forms vary, you discover how symbolic power varies from place to place" (MORETI, 2013, p. 59). The knowledge of other languages rather than English will open the door to the study of local literature instead of world literature, and, for Moretti (2013), this will not be practical in terms of understanding literature as a whole system. As said before, distant reading is independent of linguistic knowledge. Thus, we can infer that, by considering novels as part of a whole corpus, they will be transformed into data in order to make the analysis proposed by Moretti (2013). In that way, big collections of data will turn into a new definition of "text", but one question that emerges is: should a database be considered a genre? Under the perspective of distant reading, yes: we see that, in terms of close or distant reading, cognitive narratology and the digital humanities approach to literature differ, but it is necessary to point out that those are not the only approaches to be considered at the moment of contrasting them. What about the points of contact in which cognitive narratology joins digital humanities? Is the text in digital humanities taken into account only as an ensemble 
of words and sentences? Can we talk about text as a medium or interface? In the next section, I put in parallel cognitive narratology and distant reading in order to look for their contact points.

\section{COMMON POINT WITH DIGITAL HUMANITIES}

In this essay, I am discussing the relationship between the reader and the text and, as I have pointed in the descriptions of both theories, there is a special idea of considering the way the reader approaches the text and, thus, which are the results of that approach. Herman (2013) argues that cognitive sciences' scholars have developed the hypothesis that the rule systems of algorithms are based on story grammars and narrative representations. The idea of a text as an algorithm in digital humanities is also stated by John Bradley in "Text tools". "Central interest of computing humanists are tools to manipulate text for scholarly purposes" (BRADLEY, 2004, p. 505). Marie Ryan (2008) says that, in the domain of artistic expression, literature is subjected to the behavior of digital objects and regulated by what she calls "the invisible code of a program". "This program often plays a double role: it presides over the creation of the text, and it displays it on the screen" (RYAN, 2008, p. 515) and she considers text as an algorithm manipulated by tools for specific purposes, which can be thought of a way of reading. This is an important contact point between both cognitive narratology and a digital humanities approach to literary studies.

Ryan (2008) continues arguing that the relationship between narrative and digital tools is given by a medium with four properties: interactivity, volatility, sensorial and semiotic, and networking capabilities. For her, digital tools are the media between the author and the reader that focus on the text's ability to create an original experience which cannot be duplicated in any other media, "an experience which makes the medium seem truly necessary [...] for the narrative meaning" (RYAN, 2008, p. 516). If we consider, thus, the medium as part of the readers' experience, understood as a semiotic and sensorial experience, then we can talk about another contact point between cognitive narratology and digital humanities approach to literary studies.

Finally, Herman (2003) states that relevant research in cognitive narratology includes studies of narrative as a resource for navigating and making sense of computer-mediated environments and this would include empirical studies for measuring reading times as methods for analyzing corpus and diagrams of story worlds. Furthermore, there is also a point in which digital reading can encompass cognitive narratology, which is a semiotic analysis to enable "interpreters (readers) to identify stories or story-like elements across any semiotic media" (HERMAN, 2013, p. 7). 


\section{CONCLUSIONS}

To conclude, cognitive narratology can be seen as a multidimensional approach towards a view that considers a process of narrative meaning and sense-making as a part of human existence. Cognitive narratology led us to think about the role of narratives as part of a posthumanist realm in which cognitive sciences thematize and reflect on the process whereby experiences are narrativized and identities narratively constituted.

In The death of the author, Barthes (2010, p. 1325) wrote: "The reader is the very space in which are inscribed, without any being lost, all the citations a writing consists of; the unity of a text is not in its origin, it is in its destination." However, despite what Barthes claims in this passage, the reader is not a blank space on which a text can be purely inscribed. The reader, just like the author, has his/her own viewpoint: the author's viewpoint seeps into his/ her writing while the reader's viewpoint shapes his/her reading. We saw that with the example of Tournier (1972). The reader has a biography, a history, and a psychology - as does the author. Is the author truly dead and only the reader truly living? With the cognitive narratology theory, we must say no to that question: the reader is a new narrator.

I have argued that the aim of cognitive narratology is to legitimate narrative as a matter of constantly reinterpreting experiences and giving meaning through reading. Thinking about reading in terms of this theory and how it can build subjectivity and identity enables us, as readers, not only to think about the conditioned nature of our narrative existence, but also to recognize the possibilities of narrating otherwise. This allows us to think about the complex mechanisms through which our narrative (texts, dialogues, emails, messages) could be socially regulated and nevertheless about how they can provide us with important insights to imagine alternative narrative identities and new modes of experience.

In cognitive narratology, narratives are essential to the human mode of giving sense to the world. The process of interpretation will, thus, always be conditioned by experiences, cultural or social, and mediated by a linguistic experience of life. This process allows us not only to consider the manner in which cultural models affect our ways of understanding and experiencing the world and ourselves, but also to acknowledge "the subject's capacity to agency and active sense-making" (MERETOJA, 2013, p. 101).

Moretti proposes a new way of approaching literature from a completely new direction: not to read texts in the traditional way (close reading), but to count, to graph, and to map or visualize them. For him, literature possesses and provides data for interpretation through a distant reading, but, as I have pointed, distant reading is not the only way in digital humanities for approaching text: one of the things that a distant reading cannot hold is that creating meaning and sense-making are not possible without the reader. The reader is socially, historically, and culturally situated and relational, and meaning and sense are constituted by a personal and complex network of experiences. 


\section{Leitura em narratologia cognitiva e leitura distante na abordagem das humanidades digitais}

Resumo: Este ensaio propõe fazer uma comparação entre a narratologia cognitiva, que estuda a narrativa em suas diversas formas, enfatizando os processos mentais/biológicos como semelhantes no leitor e autor, e a abordagem de leitura distante das humanidades digitais que identifica sistemas e formas literárias mais globais com o computador como uma ferramenta para interpretação. As principais ideias de narratologia cognitiva desenvolvidas por um de seus principais teóricos, David Herman, são apresentadas enfocando a definição e as relações entre leitor e texto. A narratologia cognitiva como abordagem interdisciplinar para a leitura atenta é mencionada para dialogar com os principais tópicos da abordagem literária das humanidades digitais, especialmente as ideias delineadas por Franco Moretti. 0 contraste entre ambas as abordagens se concentrará no papel do leitor, encontrando alguns pontos de contato entre elas.

Palavras-chave: Humanidades digitais. Leitura distante. Narratologia cognitiva. Leitura próxima. Experiência de leitura.

\section{REFERENCES}

BARTHES, R. The dead of the author. In: LEITCH, V. B.; CAIN, W. E.; FINKE, L. A. (ed.). The norton anthology of theory and criticism. New York: Norton, 2010. p. 1316-1331.

BRADELY, J. Text tools. In: SCHREIBMAN, S.; SIEMENS, R.; UNSWORTH, J (ed.). A companion to digital humanities. Oxford: Blackwell, 2004. p. 505-525.

SAUSSURE, F. de. Course in General Linguistics. In: LEITCH, V. B.; CAIN, W. E.; FINKE, L. A. (ed.). The norton anthology of theory and criticism. New York: Norton, 2010. p. 845-866.

FISH, S. Interpreting the ariorum. In: LEITCH, V. B.; CAIN, W. E.; FINKE, L. A. (ed.). The norton anthology of theory and criticism. New York: Norton, 2010. p. 1970-1992.

FLUDERNIK, M. Histories of narrative theory (II): from structuralism to the present. In: PHELAN, J.; RABINOWITZ, P. J. A companion to narrative theory. New Jersey: John Wiley \& Sons, 2008. p. 36-59.

HERMAN, D. Cognitive narratology. In: HÜHN, P.; PIER, J.; SCHMID, W.; SCHÖNERT, J. The living handbook of narratology. Hamburg: Hamburg University, 2013. p. 5-20. Available at: https://www.Ihn.uni-hamburg.de/node/38.html/. Accessed on: Oct. 42021.

HERMAN, D. Multimodal storytelling and identity construction in graphic narrative. In: SCHIFFRIN, D.; DE FINA, A.; NYLUND, A. Telling stories: language, narrative, and social life. Washington: Georgetown University Press, 2008. p. 195-208. 
HERMAN, D. Narrative theory and the cognitive sciences. Stanford: CLS Stanford, 2003.

HERMAN, D. The emergence of mind: representations of consciousness in narrative discourse in English. Nebraska: University of Nebraska Press, 2011.

JÄNICKE, S.; FRANZINI, G.; SCHEUERMANN, G.; CHEEMA, M. F. On close and distant reading in digital humanities: a survey and future challenges. In: EUROVIS: THE EG/VGTC CONFERENCE ON VISUALIZATION, 2015. Cagliari. Proc. of EuroVis-STARs, 2015. p. 83-103.

KIRSCHENBAUM, M. What is digital humanities and what's it doing in English departments? In: GOLD, M. K. (ed.). Debates in the digital humanities. Minnesota: University of Minnesota Press, 2012. p. 3-11.

MERETOJA, H. Philosophical underpinnings of the narrative turn in theory and fiction. In: HATAVARA, M.; HYDÉN, L.-C.; HYV̈̈RINEN, M. (ed.). The travelling concepts of narrative. New York: John Benjamins, 2013. p. 93-118. (Studies in Narrative, 18).

MORETTI, F. Distant reading. New York: Verso Books, 2013.

MORETTI, F. Graphs. In: LEITCH, V. B.; CAIN, W. E.; FINKE, L. A. (ed.). The norton anthology of theory and criticism. New York: Norton, 2010. p. 2438-2464.

ROMMEL, T. Literary studies. In: SCHREIBMAN, S.; SIEMENS, R.; UNSWORTH, J (ed.). A companion to digital humanities. Oxford: Blackwell, 2004. Available at: http://www. digitalhumanities.org/companion/. Accessed on: Oct. 42021.

RYAN, M.-L. Narrative and digitality: learning to think with the medium. In: PHELAN, J.; RABINOWITZ, P. J. A companion to narrative theory. New Jersey: John Wiley \&t Sons, 2008. p. 515-528.

SHA, N. The reader in digital humanities. Digital Media and Learning Central, 2015. Available at: https://dmlcentral.net/the-reader-in-digital-humanities/. Accessed on: Oct. 42021.

TOURNIER, M. Vendredi ou les limbes du Pacifique. Paris: Gallimard, 1972. 